УДК 547.9:615.32:543.544

\title{
НОВЫЙ ПЕРСПЕКТИВНЫЙ РАСТИТЕЛЬНЫЙ ИСТОЧНИК D-ПИНИТОЛА, ОБЛАДАЮЩЕГО АНТИДИАБЕТИЧЕСКИМИ И ГИПОГЛИКЕМИЧЕСКИМИ СВОЙСТВАМИ
}

\author{
(C) А.М. Альмагамбетов ${ }^{1}$, Б.С. Темиргазиев ${ }^{1}$, И.В. Заварзин ${ }^{2}$, В.В. Качала ${ }^{2}$, П.К. Кудабаева ${ }^{1}$, \\ Б.И. Тулеуов ${ }^{1}$, С.М. Адекенов ${ }^{\text {* }}$ \\ ${ }^{1}$ АО «Международный научно-производственный холдине «Фитохимия», \\ ул. Газалиева, 4, Караганда, 100009 (Казахстан), e-mail: phyto_pio@mail.ru \\ ${ }^{2}$ Институт органической химии им. Н.Д. Зелинского РАН, Ленинский пр., 47, \\ Москва, 119991 (Россия), e-mail: zavi@ioc.ac.ru
}

Ранее установлено, что фитоэкдистероиды - важные вторичные метаболиты растений впервые в роде Silene L. Смолевка семейства Caryophyllaceae Juss. (Гвоздичные) были обнаружены в растениях Silene praemixta M.Pop., затем в Silene brahuica Boiss.

В представленной статье нами проведено комплексное изучение химического профиля смолевки брагуйской (Silene brahuica Boiss.), собранной в Южно-Казахстанской области в природных местообитаниях и соответственно является перспективным промышленно-доступным источником вышеуказанных важных продуктов вторичного обмена растений.

Цель работы - фитохимическое исследование надземной части смолевки брагуйской на присутствующие в растении сопутствующие биологически активные вещества, с использованием метода ВЭЖХ и колоночной хроматографии.

Установлено, что при водно-этанольной, а затем и изобутанольной экстракции основными компонентами являются фитоэкдистероиды и впервые выделенный с количественным выходом из данного растения циклический полиол. Тонкое строение D-пинитола (1S,2S,4S,5R)-6-метоксициклогексан-1,2,3,4,5-пентол), обладающего антидиабетическими и гипогликемическими свойствами, охарактеризовано с использованием ЯMP ${ }^{1} \mathrm{H},{ }^{13} \mathrm{C}$ (HSQC, COSY, NOESY)спектроскопии.

Ключевые слова: Silene brahuica Boiss, изобутанольный экстракт, высокоэффективная жидкостная хроматография, D-пинитол, фитоэкдистероиды, экдистерон.

\section{Введение}

Среди разнообразных низкомолекулярных биологически активных веществ (БАВ) - продуктов вторичного обмена растений - заметное место занимают экдистероиды. Значительное большинство экдистероидов, представляющих собой группу близких по химическому строению полигидроксилированных стероидов, являются естественными гормонами членистоногих, регулирующими процессы линьки и метаморфозы $[1,2]$. Принципиально отличаясь по механизму регуляции процессов белкового синтеза у млекопитающих от стеранаболов, отсутствию специфических гормональных эффектов,

Альмагамбетов Алибек Муратович - магистрант, младший научный сотрудник лабораторий химии стероидных соединений, e-mail: arglabin@phyto.kz Темиргазиев Бахтияр Серикович - докторант $\mathrm{PhD}$, магистр технических наук, младший научный сотрудник лабораторий химии стероидных соединений, e-mail:arglabin@phyto.kz

Заварзин Игорь Викторович - заведующий лабораторией химии стероидов, доктор химических наук, e-mail: zavi@ioc.ac.ru

Качала Вадим Вадимович - заведующий лабораторией, кандидат химических наук, e-mail: zavi@ioc.ac.ru

Продолжение на с. 80. характерных для данных препаратов на основе тестостерона, они представляют значительный интерес для создания на их основе адаптогенных, актопротекторных и иммуномодулирующих средств. Наиболее эффективные из них - экдистерон (I) и туркестерон - проявляют гипогликемическое и выраженное сахароснижающее действие [3].

Исследования показали, что и другие структурно схожие циклические полигидроксилированные БАВ: ресвератрол (3,5,4-тригидрокси-

\footnotetext{
* Автор, с которым следует вести переписку.
} 
транс-стильбен) (II) и $\mathrm{D}$-пинитол (1S,2S,4S,5R)-6-метоксициклогексан-1,2,3,4,5-пентол) (III) обладают также выраженными гипогликемическим и антидиабетическим эффектами.

В частности, D-пинитол используется в качестве гипогликемического и антидиабетического лекарственного средства в США [4].

Ранее сообщалось о выделении данного ценного циклополиола из клевера лугового (Trifolium pratense L.) впервые [5].<smiles>CC(C)(O)CC[C@@H](O)[C@](C)(O)C1CC[C@]2(O)C3=CC(=O)[C@H]4C[C@H](O)[C@@H](O)C[C@]4(C)C3CC[C@]12C</smiles>

(I)<smiles>Oc1ccc(/C=C/c2cc(O)cc(O)c2)cc1</smiles>

(II)<smiles>COC1C(O)C(O)C(O)C(O)C1O</smiles>

(III)

Анализ литературных данных показывает, что по содержанию экдистероидов наиболее богатыми являются виды рода Silene L. (семейства Caryophyllaceae Juss.). Максимальное накопление фитоэкдистероидов в надземной части растений рода Silene L. наблюдается в фазе бутонизации и цветения [6-9].

В данной статье продолжены работы по поиску и установлению строения фитоэкдистероидов и других сопутствующих биологически активных вторичных метаболитов растений семейства Caryophyllaceae Juss. $[10,11]$ и представлены результаты изучения химического состава надземной части экдистероидсодержащего растения смолевки брагуйской (Silene brahuica Boiss). Объектом исследования выбрана надземная часть смолевки брагуйской, собранная в Южно-Казахстанской области, Каратауский хребет, ущ. Арпаозен, в фазе цветения.

Известно, что данное растение наряду с другими (Rhaponticum carthamoides, Rhaponticum integrifolium, Ajuga turkestanica) является растительным источником препарата «Экдистен» [12].

В связи с этим целью работы явилось исследование компонентного состава изобутанольного экстракта надземной части смолевки брагуйской.

\section{Экспериментальная часть}

Экстракция надземной части (листья, бутоны, стебли) измельченного воздушно-сухого сырья массой 1,0 кг проводилась четырехкратно 10 л 70\%-ным водным этанолом путем нагревания на водяной бане при температуре кипения растворителя в течение 1-1,5 ч. Экстракт охлаждали, сливали и упаривали на ротационном испарителе при температуре не выше $50{ }^{\circ} \mathrm{C}$. К полученной густой коричневой сиропообразной массе добавили 0,2 л этанола и 0,4 л воды. Далее полученный этанольный экстракт обработали смесью петролейного эфира и этилацетата в соотношении $2: 1$ (0,4 : 0,2 л) с целью удаления неполярных компонентов, оставшуюся водорастворимую часть экстрагировали изобутанолом $(0,6$ л), в результате получен густой экстракт. Изобутанольные экстракты объединили, затем отгоняли досуха под вакуумом. Получили (86,5 г) сумму экдистероидов с сопутствующими веществами в виде густой зеленой сиропообразной массы. Методом тонкослойной хроматографии (ТCX) и качественного анализа установлено наличие экдистерона (I). При многократном колоночном хроматографировании на окиси алюминия (I степени активности по Брокману, масса сор-

Кудабаева Перизат Какеновна - инженер лаборатории химии стероидных соединений, e-mail: arglabin@phyto.kz

Тулеуов Бораш Игликович - заведующий лабораторией химии стероидных соединений, доктор химических наук, професcop, e-mail: arglabin@phyto.kz

Адекенов Сергазы Мынжасарович - доктор химических наук, профессор, академик НАН РК, председатель правления АО «Международный научнопроизводственный холдинг «Фитохимия», e-mail: arglabin@phyto.kz бента 1,6 кг) и при элюировании колонки смесью хлороформ-этанол $(6: 4)$ выделено целевое индивидуальное вещество (III) $(1,0$ г) от веса воздушносухого сырья.

D-пинитол $\quad(1 \mathrm{~S}, 2 \mathrm{~S}, 4 \mathrm{~S}, 5 \mathrm{R})-6$-метоксициклогексан-1,2,3,4,5-пентол (III).

Брутто формула $\mathrm{C}_{7} \mathrm{H}_{14} \mathrm{O}_{6}\left([\alpha]_{\mathrm{d}}+65,63^{\circ}\right.$, лит. $\left([\alpha]_{\mathrm{d}}+65,63^{\circ}[5]\right)$. Выход 1,0 г. $(0,1 \%)$, белые блестящие мелкие пластинчатые кристаллы. Т.пл. 191$193{ }^{\circ} \mathrm{C}, \mathrm{R}_{\mathrm{f}}=0,52$ (хлороформ-этанол, $1: 0,1$ ). ИК 
спектр, v, см ${ }^{-1}:$ 3600-3300 (ОН), 2360-2950 (С-С), 1175 (С-О). Спектр ЯМР ${ }^{1} \mathrm{H}$ (ДМСО-d 6 ), $\delta$, м.д.: 3,05 т (Н, $\mathrm{CH}, \mathrm{J} 9,3$ Гц), 3,44 м (H, CH), 3,45 м (3H, $\left.\mathrm{OCH}_{3}\right), 3,51$ м $(1 \mathrm{H}, \mathrm{CH}), 3,64$ м $(1 \mathrm{H}, \mathrm{CH}), 3,65$ м $(1 \mathrm{H}, \mathrm{CH}), 4,29$ д $(1 \mathrm{H}, \mathrm{OH}), 4,42$ д $(1 \mathrm{H}, \mathrm{OH}) 4,47$ д $(1 \mathrm{H}, \mathrm{OH}), 4,59$ д $(1 \mathrm{H}, \mathrm{OH}), 4,68$ д $(1 \mathrm{H}, \mathrm{OH})$. Спектр ЯМР ${ }^{13} \mathrm{C}($ ДМСО-d 6$), \delta_{\mathrm{c}}$, м.д.: 72,57 (CH), 59,58 $\left(\mathrm{OCH}_{3}\right)$, 70,05 (CH), 70,89 (CH), 71,92 (CH), 72,38 (CH), 83,76 (CH).

Температуру плавления определяли на приборе Boetius. ИК-спектры снимали на спектрометре Ava$\operatorname{tar} 360$ ESP в таблетках с KBr. УФ-спектры поглощения записывали на спектрометре Helios- $\beta$. Элементный анализ проведен на анализаторе Eurovector 3000 А.

Спектры ЯMP ${ }^{1} \mathrm{H}$ и ${ }^{13} \mathrm{C}$ регистрировали на приборе Bruker AV-600 [600 МГц $\left({ }^{1} \mathrm{H}\right)$ и 125 МГц $\left.\left({ }^{13} \mathrm{C}\right)\right]$ относительно внутреннего стандарта-ТМС.

Чистоту выделенного соединения контролировали методом ТCX на пластинках Sorbfil с использованием системы хлороформ-этанол (6 : 4), а также методом ВЭЖХ (чистота 98,12\%).

\section{Обсуждение результатов}

В результате предварительных хроматографических исследований, в том числе с применением выскоэффективной жидкостной хроматографии (ВЭЖХ) установлено, что этанольный экстракт надземной части смолевки брагуйской содержит экдистероиды, среди которых основным является экдистерон (I) (количественное его содержание в экстракте составляет $0,05 \%$ ).

В результате хроматографического разделения экдистероидных фракций упаренных водноспиртовых и изобутанольных извлечений из надземной части растения выделено целевое-белое мелкокристаллическое (порошковое) вещество нестероидной природы (III). В ИК-спектре вещества (III) наблюдаются полосы валентных колебаний гидроксильных групп в области 3600-3300 см ${ }^{-1}$, алифатических С-С связей 2360-2950 см ${ }^{-1}$ и С-О связей $1175 \mathrm{~cm}^{-1}$, а в УФ-спектре и видимой области полосы поглощения отсутствуют. и DMSO.

Спектр ${ }^{1}$ Н-ЯMP соединения (III) содержат сигналы 14 протонов, а также остаточные сигналы HDO

Все сигналы протонов вещества находятся в области 2,9-4,8 м.д., что свидетельствует о наличии только алифатических атомов.

Спектр ${ }^{13} \mathrm{C}-Я M P$, записанный в режиме DEPTq $\left(\mathrm{CH}, \mathrm{CH}_{3}-\right.$ с положительными интенсивностями, $\mathrm{Cq}, \mathrm{CH}_{2}$ - с отрицательными), выявил сигналы семи атомов углерода, все с положительными интенсивностями, вероятно, эти сигналы принадлежат шести атомам углерода циклогексанового кольца, связанных с кислородной функцией (70,05-83,76 м.д.), и одному атому углерода метоксильной группы со значением химического сдвига 59,58 м.д.

Спектр ${ }^{13} \mathrm{C}$-ЯМР был отнесен при помощи спектра двумерной гетероядерной ЯМР-спектроскопии $\operatorname{HSQC}\left({ }^{1} \mathrm{H}^{13} \mathrm{C}\right)$ (рис. 1$)$.

Сигналы в области 4,2-4,9 м.д. не принадлежат ни одной СН-группе. Исходя из масс-спектра, они относятся к пяти ОН-группам [13, 14].

Спектр COSY позволил отнести протоны в этих группах и их привязку к СН-группам (рис. 2).

Как видим, СН-группа при 3,02 м.д. не присоединена к ОН-группе. В то же время химический сдвиг $13 \mathrm{C}$, равный 83,8 м.д., свидетельствует о привязке атома кислорода.

Детальное установление структуры было выполнено по спектру NOESY (рис. 3).

В данном спектре присутствуют сигналы как от ЯЭО-взаимодействий (черные кросс-пики), так и вызванные химическим обменом между ОН-протонами (голубые кросс-пики).

Исходя из возможных ЯЭО-корреляций, представляется единственно возможным строение молекулы в виде циклического полиола (III), с замещенным метилом (табл.).

На основании характера расщепления атомов в мультиплеты и величин КССВ $1 \mathrm{H}-1 \mathrm{H}$, а также выявленных ЯЭО-взаимодействий атомы Н-6,5,4 и 1 являются аксиальными в кольце, а Н-3 и 2 - экваториальными, с учетом вышесказанного, структура может быть представлена формулой III.

Таким образом, из смолевки брагуйской (Silene brahuica Boiss.) впервые выделили с количественным выходом и идентифицировали (1S,2S,4S,5R)-6-метоксициклогексан-1,2,3,4,5-пентол), D-пинитол (III). 


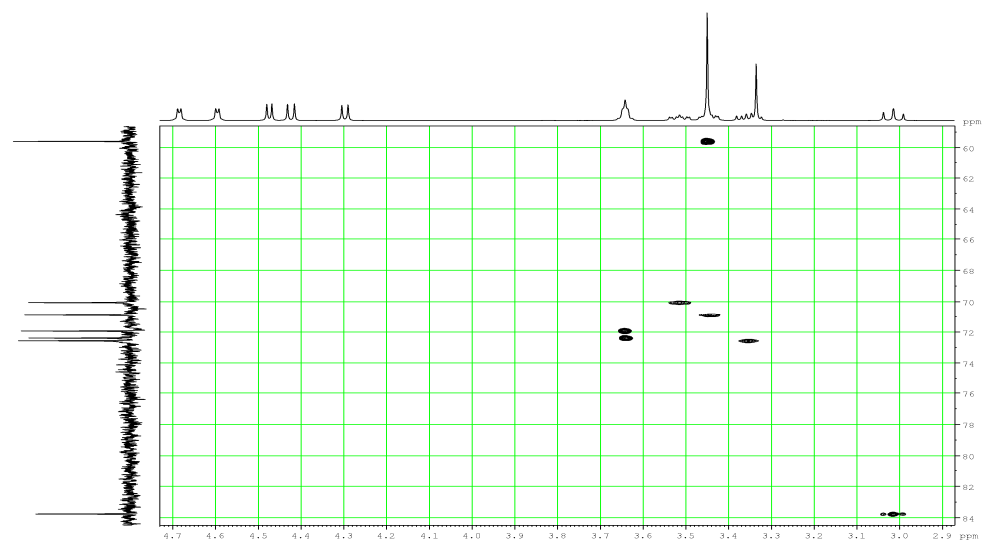

Рис. 1. HSQC $\left({ }^{1} \mathrm{H}-{ }^{13} \mathrm{C}-9 \mathrm{MP}\right)$ спектр исследуемого соединения (III)

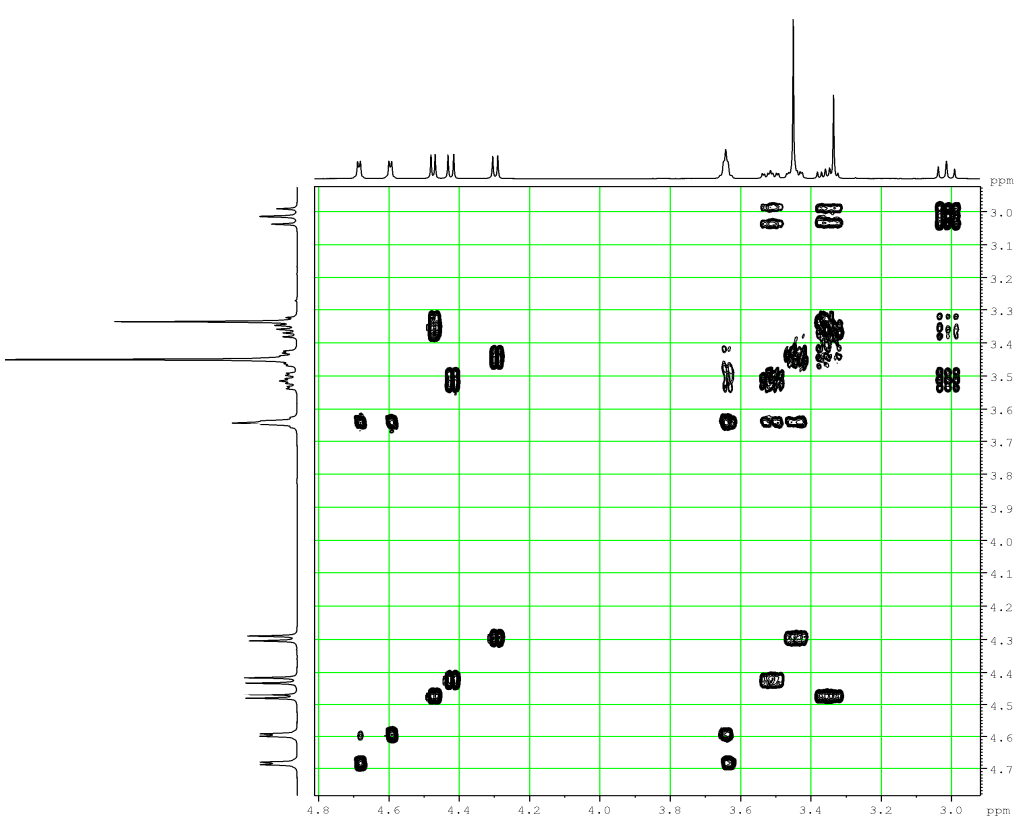

Рис. 2. $\operatorname{COSY}\left({ }^{1} \mathrm{H}-{ }^{1} \mathrm{H}\right)$ спектр исследуемого соединения (III)

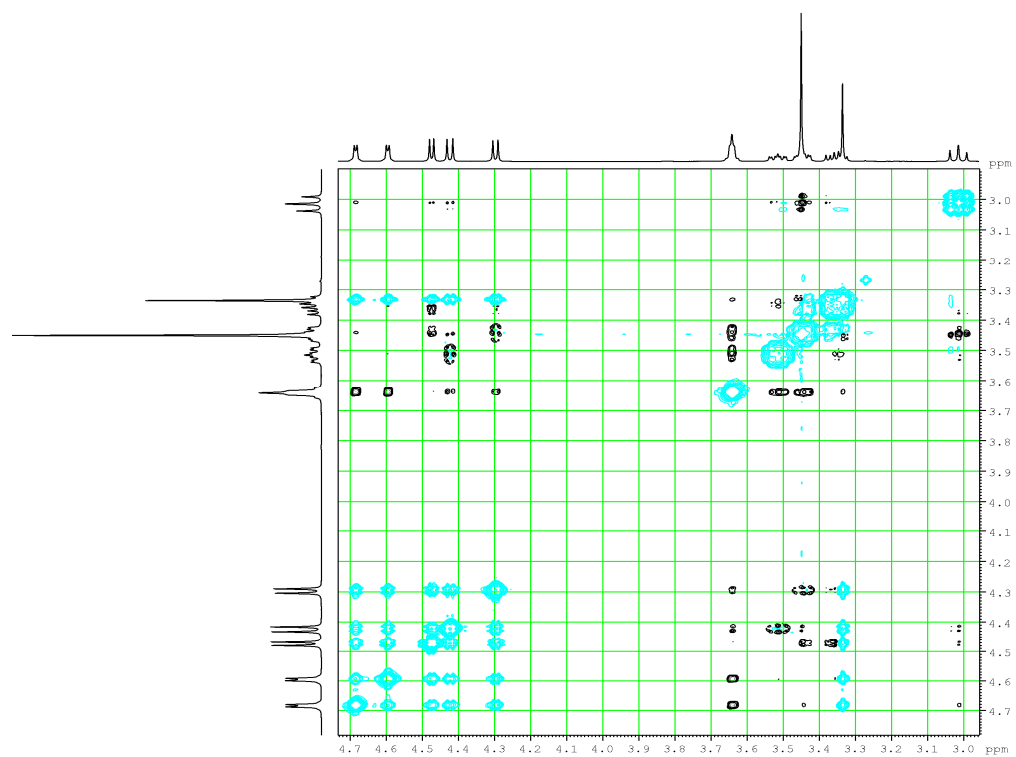

Рис. 3. NOESY $\left({ }^{1} \mathrm{H}-{ }^{1} \mathrm{H}\right)$ спектр исследуемого соединения (III) 
Данные спектров ЯМР ${ }^{1} \mathrm{H}$ и ${ }^{13} \mathrm{C}$ исследуемого соединения (III)

\begin{tabular}{c|c|c|c}
\hline Атом & ${ }^{\mathrm{H}}$ & ${ }^{13} \mathrm{C}$ & NOЕ-взаимодействия \\
\hline 1 & 3,51, м.; 4,42, д. (OH) & 70,05 & $\mathrm{H}-2,5$ \\
2 & 3,641, м.; 4,68, д. $(\mathrm{OH})$ & 72,38 & $\mathrm{H}-1,3,1-\mathrm{OH}$ \\
3 & 3,646, м.; 4,59, д. $(\mathrm{OH})$ & 71,92 & $\mathrm{H}-2,4,4-\mathrm{OH}$ \\
4 & 3,44, м.; 4,29, д. (OH) & 70,89 & $\mathrm{H}-1,2-\mathrm{OH}, 5-\mathrm{OH}$ \\
5 & 3,35, м.; 4,47, д. (OH) & 72,57 & $\mathrm{H}-1,4,5-\mathrm{OH}$ \\
6 & 3,05, т. J=9,3 Гц & 83,76 & $\mathrm{H}-1,4,5,1-\mathrm{OH}, 2-\mathrm{OH}, 5-\mathrm{OH}$ \\
6-OCH & 3,45, с. & 59,58 & $\mathrm{H}-4$ \\
\hline
\end{tabular}<smiles>CO[C@@H]1[C@H](O)[C@@H](O)[C@H](O)[C@@H](O)[C@H]1O</smiles>

(III)

\section{Вblводbl}

1. Установлено, что при водно-этанольной, а затем и изобутанольной экстракции надземной части смолевки брагуйской основными компонентами являются фитоэкдистероиды и впервые выделенный с количественным выходом из данного растения циклический полиол - D-пинитол.

2. Тонкое строение D-пинитола (1S,2S,4S,5R)-6-метоксициклогексан-1,2,3,4,5-пентол) полностью охарактеризовано с использованием ЯMP ${ }^{1} \mathrm{H},{ }^{13} \mathrm{C}(\mathrm{HSQC}, \mathrm{COSY}, \mathrm{NOESY})$-спектроскопии.

3. Показано, что благодаря высокому содержанию D-пинитола (1,0 г от веса воздушно-сухого сырья), обладающего антидиабетическими и гипогликемическими свойствами, растительное сырье смолевки брагуйской перспективно использовать в качестве промышленно-значимого источника получения целевого продукта.

\section{Список литературы}

1. Ахрем А.А., Ковганко Н.В. Экдистероиды: химия и биологическая активность. Мн., 1989. С. 327.

2. Тулеуов Б.И. Стероидные соединения растений и лекарственные препараты на их основе. Поиск, химическая модификация и практические аспекты применения. Караганда, 2009. 208 с.

3. Сыров В.Н., Юлдашева Н.Х., Эгамова Ф.Р., Исмаилова Г.И., Абдуллаев Н.Д., Хушбактова З.А. Оценка гипогликемического действия фитоэкдистероидов // Экспериментальная и клиническая фармакология. 2012. T. 75, №5. C. 28-31.

4. Misra L.N., Siddiqi S.A. Dhaincha (Sesbania bispinosa) leaves: A good source of antidiabetic (+)-pinitol // Current Science. 2004. Vol. 87. N11. P. 1507.

5. Дренин А.А., Ботиров Э.Х., Туров Ю.П. Новый гликозид изофлавона из Trifolium pratense L. // Химия растительного сырья. 2010. №2. С. 53-56.

6. Эшмирзаева Н.Э., Хидырова Н.К., Ходжаева М., Межлумян Л.Г., Шахидоятов Х.М. Химический состав растения Silene viridiflora // Химия природных соединений. 2005. №4. С. 365-366.

7. Воробьева А.Н., Рыбин В.Г., Зарембо Е.В., Болтенков Е.В. Фитоэкдистероиды Stemmacantha uniflora // Химия природных соединений. 2006. №6. С. 604-605.

8. Рамазанов Н.Ш., Мамадалиева Н.З., Бобаев И.Д. Фитоэкдистероиды растений пяти видов рода Silene // Химия природных соединений. 2007. №1. С. 97-98.

9. Zibareva L., Yeromina V.I., Munkhjargal N., Girault J.P, Dinan L., Lafont R. The phytoecdysteroid profiles of 7 species of Silene (Caryophyllaceae) // Arch. Insect. Biochem. Physiol. 2009. Vol. 72. N4. Pp. 234-248.

10. Тулеуов Б.И. Исследование некоторых представителей семейств Asteraceae и Caryophyllaceae на содержание 20-гидроксиэкдизона // Химия природных соединений. 2009. №5. С. 636-637.

11. Тулеуов Б.И., Турдыбеков К.М., Хабдолда Г., Адекенов С.М., Нуркенов О.А., Тулеуова Б.К., Кожанова А.М., Альмагамбетов А.М. Строение и стереохимия фитоэкдизона из смолевки меловой (Silene Cretaceae Fisch.) // Журнал общей химии. 2014. Т. 84, вып. 4. С. 625-628.

12. Рамазанов Н.Ш. Экдистероиды растений родов Silene, Rhaponticum и Ajuga : автореф. дис. ... докт. хим. наук. Ташкент, 2007. $49 \mathrm{c}$.

13. Anderson A.B., MacDonald D.L., Fischer H.O.L. The Structure of Pinitol // J. Am. Chem. Soc. 1952. Vol. 74. N6. Pp. 1479-1480.

14. Плиев Т.Н. Молекулярная спектроскопия : в 5 т. Владикавказ, 2004. Т. 3. 600 с.

Поступило в редакцию 29 декабря 2015 2. 
Almagambetov A.M. ${ }^{l}$, Temirgaziev B.S. ${ }^{l}$, Zavarzin I.V. ${ }^{2}$, Kachala V.V. ${ }^{2}$, Kudabaeva P.K. ${ }^{l}$, Tuleuov B.I. , Adekenov S.M. ${ }^{1 *}$ NEW PROSPECTIVE HERBAL SOURCE OF D-PINITOLA POSSESSING ANTI-DIABETIC AND HYPOGLYCEMIC PROPERTIES

${ }^{I}$ JSC «International research and production holding «Phytochemistry», ul. Gazalieva, 4, Karaganda, 100009

(Kazakhstan), e-mail:phyto_pio@mail.ru

${ }^{2}$ N.D. Zelinsky Institute of organic chemistry of Russian Academy of Sciences, Leninsky pr., 47, Moscow, 119991

(Russia),e-mail:zavi@ioc.ac.ru

It is earlier established that phytoecdysteroids - important secondary metabolites of plants, for the first time in the genus Silene L. - Silene of Caryophyllaceae Juss family. (Caryophyllaceae) were found in plants of Silene praemixta M.Pop., then in Silene brahuica Boiss.

In the submitted article we carried out complex studying of a chemical profile of Silene brahuica Boiss., which is collected in the Southern region of Kazakhstan in natural habitats and is respectively prospective industrial and available source of the above mentioned important products of the secondary exchange of plants.

The purpose of work was phytochemical research of elevated part of Silene brahuica Boiss. on the accompanying biologically active agents which are present in plant, with use of the HPLC method and columnar chromatography.

It is established that at aqueous ethanol, and then isobutanol extraction the main components are phytoecdysteroids and for the first time cyclic polyol isolated with a quantitative exit from this plant. The thin structure of D-pinitola (1S,2S,4S,5R)-6methoxycyclohexane-1,2,3,4,5-pentol), possessing anti-diabetic and hypoglycemic properties are characterized with use of NMR1H, 13C (HSQC, COSY, NOESY) - spectroscopy.

Keywords: Silene brahuica Boiss, isobutanol extract, high-performance liquid chromatography, D-pinitol, phytoecdysteroids, ecdysterone.

\section{References}

1. Akhrem A.A., Kovganko N.V. Ekdisteroidy: Khimiia i biologicheskaia aktivnost'. [Ecdysteroids: Chemistry and Biological Activity]. Minsk, 1989, p. 327. (in Russ.).

2. Tuleuov B.I. Steroidnye soedineniia rastenii $i$ lekarstvennye preparaty na ikh osnove. Poisk, khimicheskaia modifikatsiia i prakticheskie aspekty primeneniia. [The steroid compounds of plants and drugs based on them. Search, chemical modification and practical aspects of the application]. Karaganda, 2009, 208 p. (in Russ.).

3. Syrov V.N., Iuldasheva N.Kh., Egamova F.R., Ismailova G.I., Abdullaev N.D., Khushbaktova Z.A. Eksperimental'naia i klinicheskaia farmakologiia, 2012, vol. 75, no. 5, pp. 28-31. (in Russ.).

4. Misra L.N., Siddiqi S.A. Current Science, 2004, vol. 87, no. 11, p. 1507.

5. Drenin A.A., Botirov E.Kh., Turov Iu.P. Khimiia rastitel'nogo syr'ia, 2010, no. 2, pp. 53-56. (in Russ.).

6. Eshmirzaeva N.E., Khidyrova N.K., Khodzhaeva M., Mezhlumian L.G., Shakhidoiatov Kh.M. Khimiia prirodnykh soedinenii, 2005, no. 4, p. 365-366. (in Russ.).

7. Vorob'eva A.N., Rybin V.G., Zarembo E.V., Boltenkov E.V. Khimiia prirodnykh soedinenii, 2006, no. 6, pp. 604 605. (in Russ.).

8. Ramazanov N.Sh., Mamadalieva N.Z., Bobaev I.D. Khimiia prirodnykh soedinenii, 2007, no. 1, p. 97-98. (in Russ.).

9. Zibareva L., Yeromina V.I., Munkhjargal N., Girault J.P, Dinan L., Lafont R. Arch. Insect. Biochem. Physiol., 2009, vol. 72, no. 4, pp. 234-248.

10. Tuleuov B.I. Khimiia prirodnykh soedinenii, 2009, no. 5, p. 636-637. (in Russ.).

11. Tuleuov B.I., Turdybekov K.M., Khabdolda G., Adekenov S.M., Nurkenov O.A., Tuleuova B.K., Kozhanova A.M., Al'magambetov A.M. Zhurnal obshchei khimii, 2014, vol. 84, no. 4, pp. 625-628. (in Russ.).

12. Ramazanov N.Sh. Ekdisteroidy rastenii rodov Silene, Rhaponticum i Ajuga: Avtoref. dis. ... dokt. khim. nauk. [Ecdysteroids Silene genera of plants, Rhaponticum and Ajuga: Author. Dis. ... Doctor. Chem. sciences]. Tashkent, 2007, 49 p. (in Russ.).

13. Anderson A.B., MacDonald D.L., Fischer H.O.L. J. Am. Chem. Soc., 1952, vol. 74, no. 6, pp. 1479-1480.

14. Pliev T.N. Molekuliarnaia spektroskopiia. [Molecular spectroscopy]. Vladikavkaz, 2004, vol. 3, 600 p. (in Russ.).

Received December 29, 2015

Revised April 27, 2016

\footnotetext{
* Corresponding author.
} 